\title{
IDEATION, REALIZATION AND EXPERIMENTATION OF PROTOTYPE DEVICE FOR MEASURING FARM TRACTOR FUEL CONSUMPTION DURING DYNO TESTS
}

\author{
Marco Bietresato, Fabrizio Mazzetto \\ Libera Universita di Bolzano, Italy \\ marco.bietresato@unibz.it
}

\begin{abstract}
One of the most difficult practical problems to overcome when testing agricultural machines (tractors) at the dyno is measuring the fuel consumption and assessing the engine's global efficiency. Indeed, diesel engines have two fuel-lines: a delivery line (from the tank to the cylinders), and a return line, to convey back in the tank the fuel not injected as a consequence of the accelerator position and pump settings. In principle, to measure the consumption, known the delivery flowrate (proportional to the engine speed), a single flowmeter could be used in the return line only (having a variable flow); unluckily, the real suction flowrate is generally unknown, varying with the model and vehicle age (i.e., with the pump components' wear), so two flowmeters are always needed. But there is another metrological problem to consider: a flowmeter inserted in series in a fuel-supply line could significantly alter the flowrate. Finally, another further problem can arise, when the experimenters are asked to characterize machines not owned by them: modifications to the vehicle under test should be avoided or, at least, limited, e.g., not to void the guarantee. Unfortunately, solutions like the clamp-on ultrasonic flowmeters (placed outside the pipes) are not so suitable for fluids with few particles in suspension, e.g., the fuel processed by the pump. Therefore, it was decided to act upstream of the entire supply line, providing an external tank placed on a precision scale near the tractor, to be used instead of the vehicle's tank. The only, absolutely reversible, needed operation is to connect to the fuel pump two flexible pipes drawing from the external tank. The device gives the net fuel consumption by means of a data logger that acquires the tank mass at periodic intervals. It has been successfully tested on a New Holland 4020V tractor at the dyno, allowing to calculate the instant/hourly/specific consumptions and the engine's global efficiency at six engine speeds (from 800 to $2200 \mathrm{rpm}$ ) and full throttle.
\end{abstract}

Keywords: fuel-consumption meter, agricultural machines, diesel engines, dyno test, real-time measurements.

\section{Introduction}

The average mass/volumetric fuel consumption (or, simply, "fuel consumption") is measured by the mass/volume of fuel used by an agricultural machine during a specific time-period (typically: in $\left.\mathrm{kg} \cdot \mathrm{h}^{-1}, \ell \cdot \mathrm{h}^{-1}\right)$. If the time-period is very short, it is possible to have the instantaneous volumetric fuel consumption $\left(\mathrm{g} \cdot \mathrm{s}^{-1}\right)$, expressed as a function of the engine load and speed. The knowledge of the fuel consumptions is a key-point for characterizing the agricultural machinery [1] for several reasons:

- the fuel consumption is one of the main parameters for comparing the performances of the driving machines involved in different field-operations (therefore, being equal the effects/achieved results on the field); furthermore, this parameter is greatly taken into account by the end users, because it is linked to the operating costs of the considered machine (it is one of the main income-statement items of ordinary expenditure in agricultural operations); at this regard Siemens and Bowers [2] affirmed that, "depending on the type of fuel and the amount of time a tractor or machine is used, fuel and lubricant costs will usually represent at least 16 percent to over 45 percent of the total machine costs";

- during experimentation/homologation sessions, it allows calculating the specific (mass) fuel consumption $c_{s}$ (in $\left.\mathrm{g} \cdot(\mathrm{kWh})^{-1}\right)$, known the power delivered by the engine in some operating conditions (engine load and speed); then, the specific consumption allows calculating the engine's global efficiency $\eta$, known the characteristics of the used fuel (in terms of lower heating value $\left.-L H V_{\text {fuel }}\right)$ [3].

The fuel consumption estimates used in cropping and machinery budgets are based on the average annual fuel consumption as indicated by the agricultural machinery management engineering practices reported in the ASAE Standards. These equations model fuel consumptions using the maximum engine power detected at the power-take-off (PTO) but, as demonstrated in [3], they give an estimation that is $15 \%$ higher than reality. Among the possibility of measuring the fuel consumptions, the simplest solution includes the calculation of the average fuel consumption at the end of a given operation/period/processed area by refuelling the tank at the initial level [4;5]; the problem of this method, however useful in some contexts in which we want to compare long-term consumptions and 
homogeneous operations, is that it loses any detail on instant consumptions. An evolution of this system can be found in [6], in which fuel consumption was measured "by using a secondary tank of 8litre capacity with a level-marked tube and bulb with volume $138.6 \mathrm{~cm}^{3}$. The secondary tank was installed and connected to the tractor fuel tank through hoses and two valves". To measure the fuel consumption during a specific field operation, the secondary tank was utilized through the valves to periodically fill the bulb (i.e., a beaker) and this one to feed the engine. This system, although effective, is based on discrete volumes of fuel and, basically, the difference between different fuel requests by the motor is calculated in term of time-interval between two subsequent refilling operations of the bulb.

Rather, in an experimental context, where a higher detail is needed, several methods for measuring fuel consumption have been hitherto proposed. All these methods can be divided in two main groups:

1. Solutions measuring directly the fuel flow-rate, hence making use of proper instruments inserted along the fuel pipe (including also the fuel-gauges already present on the machines installed by the manufacturer); in diesel engines these instruments can be one or two, respectively, if measuring the flow rate only in the fuel-supply line from the tank to the pump or also in the fuelreturn line toward the tank;

2. Solutions measuring indirectly the fuel flow-rate by exploiting its definition, i.e. a volume/mass over the time (this is the "chrono-gravimetric" principle); although these solutions make necessary use of two instruments, one for measuring the volume/mass (e.g., a recipient or a scale), another one for measuring the time, their use can be generally preferable, as they do not alter at all the fuel line (in term of local friction-losses).

Among the solutions of the first type, there is, for example, the system indicated in the articles [7; 8], in which one (or two) flow-meter(s) is(/are) inserted in series in the fuelling circuit. In [9] two turbine flow-transducers having ranges of respectively 0.1 and $2.5 \ell \cdot \mathrm{min}^{-1}$ ("VISION-1000" by Remag, Bern, Switzerland) were used. One transducer was placed between the fuel filter and the injector pump of the tractor; another one was used to measure the fuel in excess returning from both injectors and the injection pump to the fuel tank. The same transducer has been used also in [10]. Other very popular transducers are the "Aquametro VZO 4 OEM" [11; 12] and the "AIC-4004 VERITAS" [13], two volumetric sensors based on the rotation of an eccentric rotor (also called "rotary piston"). In [14] another positive-displacement turbine ("Flowtronic 215/217") is used, made up by four pistons. Other systems, like the one used in [15] (vibrating U-shaped tube exploiting the Coriolis effect; "AVL 7351"), are very interesting, but they are designed for laboratory applications only, to be positioned alongside an engine test bench.

Monitoring the fuel consumptions in the rural sector is also important, when it concerns the transport of people, other than agricultural products. For example, in [16], a differential flowmeter (a DWF Hall sensor) connected to the suction pipe and the return pipe of a bus fuel-system was used. The fuel consumptions were then converted into energy to compare two different fuels (gasoline, diesel fuel). In the same work a car was also examined: in this case the consumption has been acquired through the OBD (On-Board Diagnostics), making use of the built-in sensors. A similar solution, using in this case the Cummins built-in diagnostic system, was also used in [17] and in [18]; in this latter case, the data were collected at the end of each week, by means of an automatic datatransmission system. In [19], the vehicle speed, the engine speed, the fuel consumption rate and the throttle opening was also logged via an OBD device. However, using the OBD-connection is not a proper experimental solution, because it makes use of sensors, which characteristics/operating mode are totally unknown to the experimenters. Moreover, this solution cannot be applied to all tractors, but only to those ones having an accessible CAN-BUS system, i.e. with a known data-communicationprotocol (this is clearly a subset of the most recent machines).

All the above-described solutions are not very practical in the present case. In fact, if they have the undeniable advantage to have a high precision and to find easily a place somewhere under the bonnet, thanks to their compactness, the use of these instruments poses the following problems:

- they must be inserted in series in the fuel line(s), with minor but necessary modifications to be done on the machine that generally is not of property of the experimenters and which can be 
under guarantee; moreover, this insertion causes a concentrated head-loss that could lower the flow-rate in the fuel line and, hence, the values read with the instrument could be different than the flow-rates without the gauge;

- ideally, any of these solutions should be duplicated, because in diesel systems there are always two supply lines (one with a flow directed from the tank to the injectors and one with a flow directed in the opposite direction, to constitute the flow of diesel fuel not injected into the combustion chambers, a situation that occurs especially at partial loads);

- they do not allow a quick (and complete) change of fuel during some experiments, since the accumulation volume for the fuel is the tank of the tractor/agricultural machine.

If the primary need for the experimenters is not to modify at all the fuelling line by inserting sensors, it is theoretically possible acting also on the exhaust line, more accessible because discharging into the atmosphere. Indeed, it is possible to measure the fuel flow-rate by measuring the exhaust gases' flow-rate, the $\mathrm{O}_{2}$ and the combustion products' concentration within the exhaust line, e.g., the $\mathrm{CO}$ and $\mathrm{CO}_{2}$ emissions. Solutions of this type, although based on correct principles (they measure quantities related to the combustion reactions products), are very difficult to be implemented and would challenge hard the sensors (especially the flow meter), as these have necessary to deal with high-temperature gases. Rather, if the aim is measuring only the combustion efficiency, there is no need to quantify the exhaust gas flow-rate and the equipment could include a gas analyser only.

The clamp-on ultrasonic flowmeters are placed outside the pipes and could be a very interesting solution without performing any modification to the fuel line [20]; however, they are not so suitable for flexible plastic/rubber pipes, i.e. for material similar to most of the fuel lines, and for fluids with few or no particles in suspension, e.g., the fuel processed by the pump. Furthermore, the precision required for applications like the present one can be given only by in-line ultrasonic flowmeters, but these devices suffer from all the above-evidenced disadvantages of the first-type solutions, except for the concentrated head-loss.

For the explained reasons, it is advisable to act on an external tank [21-23], hence using a chronogravimetric principle (systems of the second type). Such systems, although simple in their operating principle, have begun to be used only recently, probably due to the availability of cheaper and more precise weighting-systems, able to be connected to a data logger. For example, in [24] the fuel consumption of a tractor was measured by continuous weighing of an external fuel tank through a platform-scale "Mettler-Toledo KB60.2" (maximum capacity $60 \mathrm{~kg}$, resolution $1 \mathrm{~g}$ ). Therefore, the low-pressure fuel system of the tractor was opened after the fuel tank and the feed and return line were both connected to the external tank. In [25] the fuel tank was placed on a scale with a capacity very similar to the previous one ( $65 \mathrm{~kg}$ range, $1 \mathrm{~g}$ resolution, Sartorius), the state of which was read at a frequency of $1 \mathrm{~Hz}$ via RS-485 interface. In the same work, a comparison with the fuel consumption inferred from $\mathrm{CO}_{2}$ emissions is also reported: although this latter method was found to offer a superior time-response, and was relatively repeatable, it is subject to drifts and uncertainties due to uncertainties in the $\mathrm{CO}_{2}$ concentration measurement, intake air flow measurement, fuel carbon content, and simplifying assumptions, so the chrono-gravimetric method results to be better. In [26; 27] the scale had a maximum capacity of $20 \mathrm{~kg}$ and the same resolution of $1 \mathrm{~g}$. In [28] a similar experimental setup is used, even if with a scale having different characteristics ("A\&D GF-6100", with a maximum capacity of $6.1 \mathrm{~kg}$ and a resolution of $0.01 \mathrm{~g}$ ): it is more precise, but has a very low capacity (it is usually utilized in a laboratory). Moreover, it is declared a sampling rate of five samples per second, very high, but, together with the low capacity of the scale, revealing in the fact the absence of the need for experiments lasting more than 30 minutes.

Also these last solutions mentioned here are perfectible. Indeed, considering that the average fuel consumption of an actual 50-kW farm tractor performing heavy field-operations (therefore, at full load, just as during a test at the dyno) is about $12 \ell \cdot h^{-1}$ (i.e., about $0.0033 \mathrm{~kg} \cdot \mathrm{s}^{-1}=3.33 \mathrm{~g} \mathrm{~s}^{-1}$ ), an ideal system should have:

- a resolution of at least one order of magnitude greater than the magnitude order of the mass required by the fuel suction (i.e., $0.1 \mathrm{~g}$ );

- a load capacity ensuring the housing on the balance plate of a minimum quantity of diesel fuel equivalent to at least half an hour of operation (i.e., 6 litres), but, possibly, 1.5-2 times greater 
(9-12 litres), to avoid a rapid heating of the diesel fuel contained therein. Indeed, when the diesel fuel temperature rises, its physical properties (viscosity, density) change and this affects the atomization of the fuel-jet and, hence, the overall goodness of the combustion [29; 30]. This phenomenon in particular has not been taken into account by any of the scholars cited in the previous paragraphs, but it is very important so much that it has oriented our system's design, leading us to introduce a heat-removal subsystem.

Therefore, the aim of this work is to concept, realize and experiment a fuel-consumption meter system specifically thought to be used during tests of agricultural tractors at the dyno, able to overcome the limitations of direct-measurement systems in general, and of the other chronogravimetric systems in particular. The effectiveness of the system shown in this paper has been proved during a real-experimentation on a New Holland 4020V tractor fuelled with commercial diesel fuel.

\section{Materials and methods}

The fuel-consumption meter system, which has been developed and used in the experiments illustrated here, is composed of the following components (see Table 1, Fig. 1):

- a plate scale having a maximum load of $30.1 \mathrm{~kg}$ and a resolution of $0.1 \mathrm{~g}$;

- a drum for containing the fuel, having a maximum capacity of 20 litres;

- a copper coil, placed inside the bin and completely submerged by the fuel; it acts as a liquidliquid heat exchanger, because inside the coil flows refrigerated water;

- a 400-W chiller, to refrigerate the water circulating within the coil and, consequently, the fuel within the drum;

- a robust but light multipurpose garden-pump, used to make the water circulate within the chiller and the coil; note that, as the water circuit is basically a closed-loop circuit, all of the pump head is used to overcome the head-losses of the circuit, being null the difference of the height and the pressure at the suction and at the delivery;

- a jerrycan, to act as a reservoir of refrigeration water, to be filled at the beginning of each test with common tap-water;

- a plastic pallet, with dimensions able to house both the chiller and the scale (with the drum above and the coil inside it), used for an easier transportation and placement of the equipment near the tractor to be tested.

Components composing the fuel-consumption meter, together with their main technical specifications and net/gross cost (NB: VAT in Italy is the $22 \%$ of the net cost).

\begin{tabular}{|c|c|c|c|}
\hline Component & Specifications & $\begin{array}{l}\text { Cost (EUR) } \\
\text { VAT excl. }\end{array}$ & $\begin{array}{l}\text { Cost (EUR) } \\
\text { VAT incl. }\end{array}$ \\
\hline Plate scale & $\begin{array}{l}\text { "Kern DS 30K0.1L" [31]; maximum load } 30.1 \mathrm{~kg} \text {; } \\
\text { readability } 0.1 \mathrm{~g} \text {, repeatability } 0.2 \mathrm{~g} \text {, linearity } \\
0.5 \mathrm{~g} \text {; plate dimensions } 450 \times 350 \times 115 \text { (height) } \mathrm{mm} \text {; } \\
\text { power supply } 230 \mathrm{~V} / 50 \mathrm{~Hz} \text {; RS232 data interface; } \\
\text { mass } 9.5 \mathrm{~kg}\end{array}$ & 700.00 & 854.00 \\
\hline Fuel drum & $\begin{array}{l}\text { Obtained from a tinplated bucket for paintings, } \\
\text { maximum capacity of } 20 \text { litres; mass: } 2.0 \mathrm{~kg}\end{array}$ & - & - \\
\hline Coil & $\begin{array}{l}\text { Made in copper with a smooth pipe: diameter } \\
14 \mathrm{~mm} \text {, thickness } 1 \mathrm{~mm} \text {; spiral dimensions: } \\
\text { diameter } 220 \mathrm{~mm} \text {, height } 350 \mathrm{~mm}, 12.5 \text { turns; } \\
\text { overall length } 8730 \mathrm{~mm} \text { equal to } 0.35 \mathrm{~m}^{2} ; 1 / 2 \text {-inch } \\
\text { terminals; mass: } 3.2 \mathrm{~kg}\end{array}$ & 49.18 & 60.00 \\
\hline Water chiller & $\begin{array}{l}\text { "Haquoss Artika } 1200 \text { "; refrigeration fluid R-134a; } \\
\text { dimensions } 475 \times 360 \times 490 \text { (height) mm; power } \\
\text { supply } 230 \mathrm{~V} / 50 \mathrm{~Hz} \text {; maximum power } 400 \mathrm{~W} \text {, } \\
2.4 \mathrm{~A} \text {; recommended minimum } / \text { maximum water } \\
\text { flow } 1200 / 3000 \ell \cdot \mathrm{h}^{-1} \text {; mass } 22.0 \mathrm{~kg}\end{array}$ & 508.20 & 620.00 \\
\hline
\end{tabular}


Table 2 (continued)

\begin{tabular}{|c|c|c|c|}
\hline Component & Specifications & $\begin{array}{l}\text { Cost (EUR) } \\
\text { VAT excl. }\end{array}$ & $\begin{array}{l}\text { Cost (EUR) } \\
\text { VAT incl. }\end{array}$ \\
\hline $\begin{array}{l}\text { Water circulation } \\
\text { pump }\end{array}$ & $\begin{array}{l}\text { "Gardena Classic } 3000 / 4 " ; \text { maximum head } \\
36 \mathrm{~m} \text {; maximum flow rate } 3100 \ell \cdot \mathrm{h}^{-1} \\
\text { (corresponding to a } 0-\mathrm{m} \text { head); self-priming } \\
\text { up to } 7 \mathrm{~m} \text {; power supply } 230 \mathrm{~V} / 50 \mathrm{~Hz} \text {; } \\
\text { maximum power } 600 \mathrm{~W} \text {; mass } 6.5 \mathrm{~kg}\end{array}$ & 81.97 & 100.00 \\
\hline Water jerrycan & $\begin{array}{l}\text { Made in PVC; maximum capacity of } \\
20 \text { litres }\end{array}$ & 6.56 & 8.00 \\
\hline $\begin{array}{c}\text { Garden } \\
\text { hose }+ \text { connections }\end{array}$ & Made in PVC; diameter 0.5 in & 16.39 & 20.00 \\
\hline Pallet & $\begin{array}{l}\text { Made in fibre-reinforced polypropylene; } \\
\text { dimensions } 60 \times 80 \times 15.5 \text { (height) } \mathrm{cm} \text {; } \\
\text { maximum load: } 700 \mathrm{~kg} \text { (static), } 300 \mathrm{~kg} \\
\text { (dynamic); mass: } 2.8 \mathrm{~kg}\end{array}$ & 8.20 & 10.00 \\
\hline
\end{tabular}
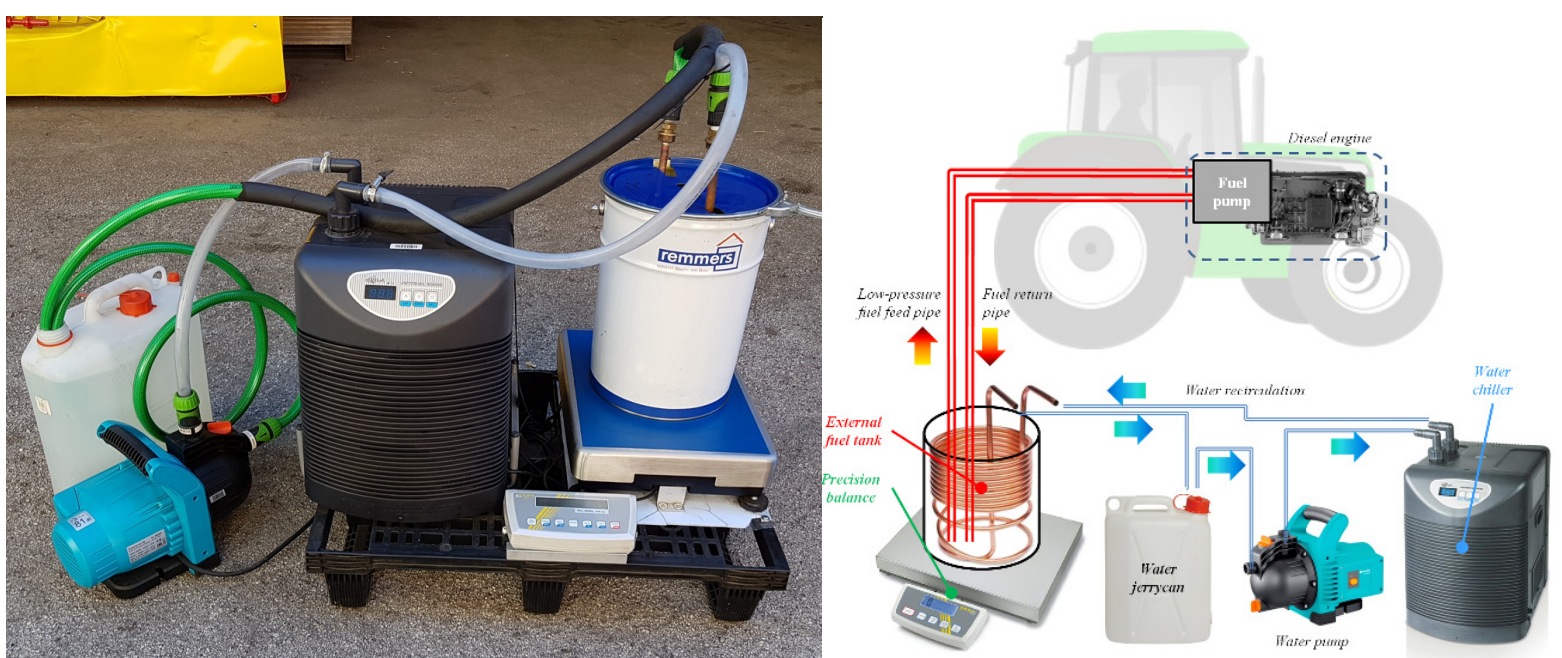

Fig. 1. Photography of palletised fuel-metering system in configuration ready to be used in test (left); scheme of utilization of system to fuel motionless tractor during test at the dyno (right)

A particular attention has been paid to the dimensioning of the cooling subsystem and to the choice of the related components. The starting point was the heat per time-unit to be dissipated not to raise the temperature of the diesel fuel in the external tank in the worst situation; the scenario of reference corresponded to the engine running at the lowest possible speed and load, hence with the minimum suction of fuel $\left(1.7 \mathrm{~g} \cdot \mathrm{s}^{-1}\right.$ at $300 \mathrm{rpm}$ for the tested tractor) and the maximum contribution of processed (i.e., heated) fuel in the tank. It is assumed that fuel is recirculated at a temperature of $80^{\circ} \mathrm{C}$ (a very high reference value, substantially equal to the engine cooling fluid temperature, chosen to dimension the system with a margin of safety). Within this hypothesis, we have selected a chiller having an electrical and thermal power higher than the thermal power to be removed from the fuel. During the experiments illustrated here, this system managed to keep the diesel fuel temperature below $41{ }^{\circ} \mathrm{C}$ with a recorded ambient temperature of $33-35^{\circ} \mathrm{C}$ in bright sunshine, thus demonstrating its effectiveness. A J-thermocouple immersed in the fuel was used to monitor the fuel temperature.

Another peculiarity of the fuel-consumption meter concerns the coil of the cooling subsystem: it is installed within the external tank, directly placed on the tank bottom; hence, it is also supported by the scale. This design-choice was suggested by the aim of having at disposal a compact system, easy to be composed and used also in an outdoor situation. Indeed, hanging the copper coil upon the scale but within the tank would have required an auxiliary frame fixed to the pallet, further complicating the system's design and raising the overall dimensions and weight of the fuel meter. Moreover, in the first experimented lab situations, described below, we had substantially-stable readings notwithstanding the water circulation circuit was active, and this convinced us of the goodness of the illustrated solution. 
As can be appreciated from Table 1, the whole system cost 1370.00 EUR (VAT excl.), i.e. 1672.00 EUR (VAT incl.), and, thanks to the chosen components and its way of operating (the tractor's feed and return line have both to be connected to flexible hoses and fuelled via the external tank), it can be really used with every type of farm tractors. Just to have a relative price-comparison, a fuel-mass flow-rate for lab-applications working on the Coriolis principle and with installation accessories (e.g., the "Siemens SITRANS F C MASS 2100 DI 1.5") has a market-price around 4000.00 EUR (VAT excl.), hence almost three times the price of the system illustrated here $(+192 \%)$. Rotary-piston transducers (e.g., the "AIC-4004 VERITAS") have a similar price, ranging from about 3200.00 to 4700.00 EUR (VAT excl.) for a complete measuring system $(+134 / 243 \%)$. Other interesting systems, specifically-thought to be installed on-board a vehicle (in series in the fuelling circuit) and including also a built-in heat exchanger and a signal conditioner (e.g., the "Gregory Flowtronic S8005C", substitute of "Flowtronic 215/217") have market-prices starting from about 16000.00 EUR (VAT excl.), i.e. more than ten times the presented system $(+1068 \%)$.

Firstly, before using it on any tractor, the explained system was verified in term of sensitivity, response speed, measurement drift to the variation of the mass supported by the scale's plate in an operative configuration (hence, with the fuel drum and the coil positioned on it). To do this, we placed a laboratory scale ("Radwag PS 6000.R2" [32]; full-scale $6000 \mathrm{~g}$, readability $10 \mathrm{mg}$, repeatability $15 \mathrm{mg}$, linearity $30 \mathrm{mg}$ ) between the plate of the scale of the fuel-consumption system and the fuel drum. By doing so, every measurement was made simultaneously by the two scales. A dropgeneration system was calibrated to let fall a water drop of $0.10 \mathrm{~g}$ every $0.33 \mathrm{~s}$ (for a total of $0.30 \mathrm{~g} \cdot \mathrm{s}^{-1}$, corresponding to about a tenth of the fuel request of a $50 \mathrm{~kW}$ farm tractor; see introduction) within the drum and a data logger was set to acquire the mass measurement from both scales. For greater convenience, the comparison was made in relation to a mass increment rather than to a mass decrement.

After this first experiment, the fuel-consumption system was then used in a real situation and in its operative configuration (i.e., with its own scale only: the "Kern DS 30K0.1L"), to measure the fuel mass over the time (sampling frequency: $1 \mathrm{~Hz}$ ) of a New Holland 4020V tractor during a test at the dyno (a "SIGMA 50 Mobile" by N. J. Froment \& Co Ltd, Easton-on-the-Hill, East Northamptonshire, England, UK [33]; maximum power $380 \mathrm{~kW}$, maximum torque $3170 \mathrm{Nm}$; Fig. 2) at full throttle.
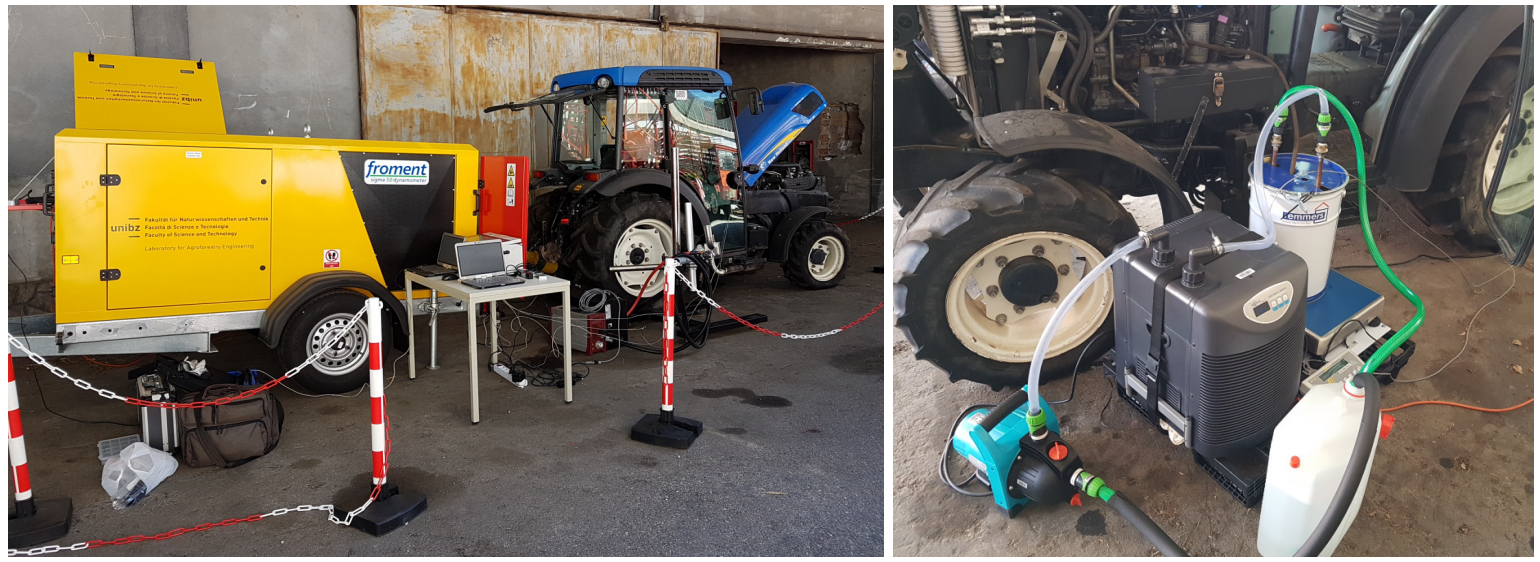

Fig. 2. Complete test-layout for farm tractor at the dyno (left); particular of fuel-consumption meter system placed at the left side of tractor (right)

The tractor fuel consumptions $\left(\ell \cdot \mathrm{h}^{-1}, \mathrm{~g} \cdot \mathrm{s}^{-1}\right)$ were determined as the first slope of the trend lines fitting the "fuel mass vs. time" scatter plot in correspondence of six engine speeds controlled by the braking torque applied by the dyno at the tractor PTO: 800-700-600-500-400-300 rpm (at the PTO). As this experiment has a usual duration of about 15 minutes, including the time periods required for the engine to warm up (at the beginning) and to stabilize at each PTO speed, any temporal variations in the Earth gravitational field and fuel loss due to evaporation were assumed to be negligible. By dividing the fuel consumption values (expressed in $\mathrm{g} \cdot \mathrm{h}^{-1}$ ) and the values of power delivered by the motor (measured by the PTO dyno, in $\mathrm{kW}$ ), the specific (mass) fuel consumption $c_{s}\left(\mathrm{~g} \cdot(\mathrm{kWh})^{-1}\right)$ has been calculated and, hence, the engine's global efficiency $\eta(\%)$, known $L H V_{\text {diesel fuel }}$ (its conventional value is equal to $10200 \mathrm{kcal} \cdot \mathrm{kg}^{-1}=42705 \mathrm{~kJ} \cdot \mathrm{kg}^{-1}=11.86 \mathrm{kWh} \cdot \mathrm{kg}^{-1}$ [34]). Indeed, it can be written: 


$$
\begin{aligned}
& \eta=\frac{E_{\text {out }}}{E_{\text {in }}}=\frac{E_{\text {out }}}{m_{\text {fuel }} \cdot L H V_{\text {fuel }}}=\frac{1}{c_{s} \cdot L H V_{\text {fuel }}} \Rightarrow \\
& \left.\Rightarrow \eta\right|_{\text {diesel fuel }}=\frac{1}{c_{s}\left(\frac{g}{k W h}\right) \cdot 11.86\left(\frac{\mathrm{kWh}}{\mathrm{kg}}\right)}=\frac{84.30\left(\frac{\mathrm{g}}{\mathrm{kWh}}\right)}{c_{s}\left(\frac{g}{k W h}\right)}
\end{aligned}
$$

where $\eta$-engine's global efficiency, \%;

$E_{i n}$ - energy entering the machine, J;

$E_{\text {out }}$ - energy going out of the machine, J;

$m_{\text {fuel }}$ - mass of the fuel, $\mathrm{kg}$;

$L H V_{\text {fuel }}$ - lower heating value of the fuel, $\mathrm{kJ} \cdot \mathrm{kg}^{-1}$ or $\mathrm{kWh} \cdot \mathrm{kg}^{-1}$;

$c_{s}$ - specific (mass) fuel consumption, $\mathrm{g} \cdot(\mathrm{kWh})^{-1}$.

\section{Results and discussion}

The first experiment has concerned the verification of the sensitivity of the fuel-consumption meter system's plate-scale to mass-variations comparable to what this system would have measured in an operative configuration. At the beginning of this experiment, a tare zero-setting procedure was followed for both used scales (laboratory high-precision scale, fuel-consumption meter system's platescale). The outputs (measured mass vs. time) of the two scales were then compared in term of graphical superposition and equations of the respective trend lines.

As visible from the trend lines' equations (Fig. 3), there is a very small misalignment of the intercepts, which can be interpreted as a constant (hence, systematic) time delay of $0.004 \mathrm{~s}$ (calculated as the difference between the two intercepts' values); this delay is statistically not significant, meaning that the response speed of the system is substantially the same of the high-precision scale, hence more than acceptable for the purposes of the fuel-consumption meter system.

The slope of the two lines is exactly the same, meaning that the scale chosen for the fuel consumption meter system is suitable to measure small mass variations (the mass of a single water drop was $0.10 \mathrm{~g}$ ) without any temporal drift, notwithstanding the presence of more than $5 \mathrm{~kg}$ of the system components already placed on it.

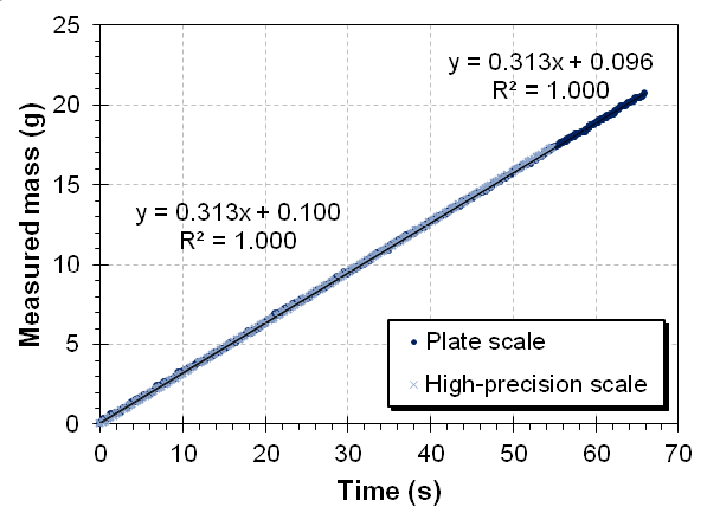

Fig. 3. Scatter plot and trend lines of mass measurements over time recorded through laboratory high-precision scale and fuel-consumption meter system's plate-scale

The second experiment was performed with the presented system on a farm tractor. Before starting to record the data, a time-synchronization of the dyno and the fuel-consumption meter system have been performed (based on the web time-signal of the atomic watch of "time.nist.gov"). The postprocessing procedure on the collected data included the following steps: (1) extraction of stretches (better: sequences of points) of the "mass measured by the scale vs. time" curve (Fig. 4) corresponding to several (here: six) stabilized PTO-speeds (the plateaux in the curve of Fig. 4), (2) plotting of the trend-lines over each of these scatter plots (Fig. 5) and calculation of their first time-derivatives (i.e., extraction of the angular coefficient of each trend-line), (3) conversion of these latter values to 
calculate the instant fuel consumption, the brake specific fuel consumption and, finally, the engine's efficiency at several engine speeds (known the conversion ratio between the PTO speed and the engine speed; Fig. 6). The small point-dispersions/fluctuations visible in Fig. 5 are due to the unavoidable pulsations of the fuel flows in the fuel system and to probable vibrations transmitted through the fuel lines (it is impossible to distinguish these two contributions, as they are always concomitant; instead, the water recirculation line does not contribute very much in this sense, as resulted also from the previous trials). However, even if present, these dispersions are very limited and the general trends are well-delineated: the R-squared values are high for all the PTO-speeds (Fig. 5).
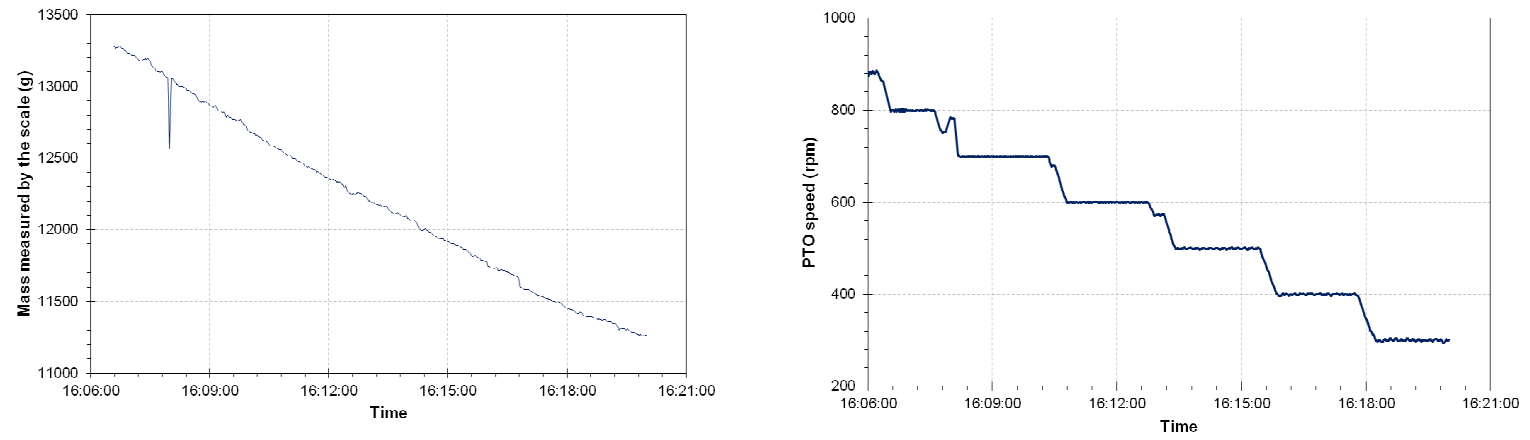

Fig. 4. (left) Complete "mass measured by scale vs. time" curve, covering entire duration of test at the dyno; as can be appreciated, the slope of the curve is not constant (there are different values at the different PTO-speeds); (right) recording of PTO speed over time during test at the dyno
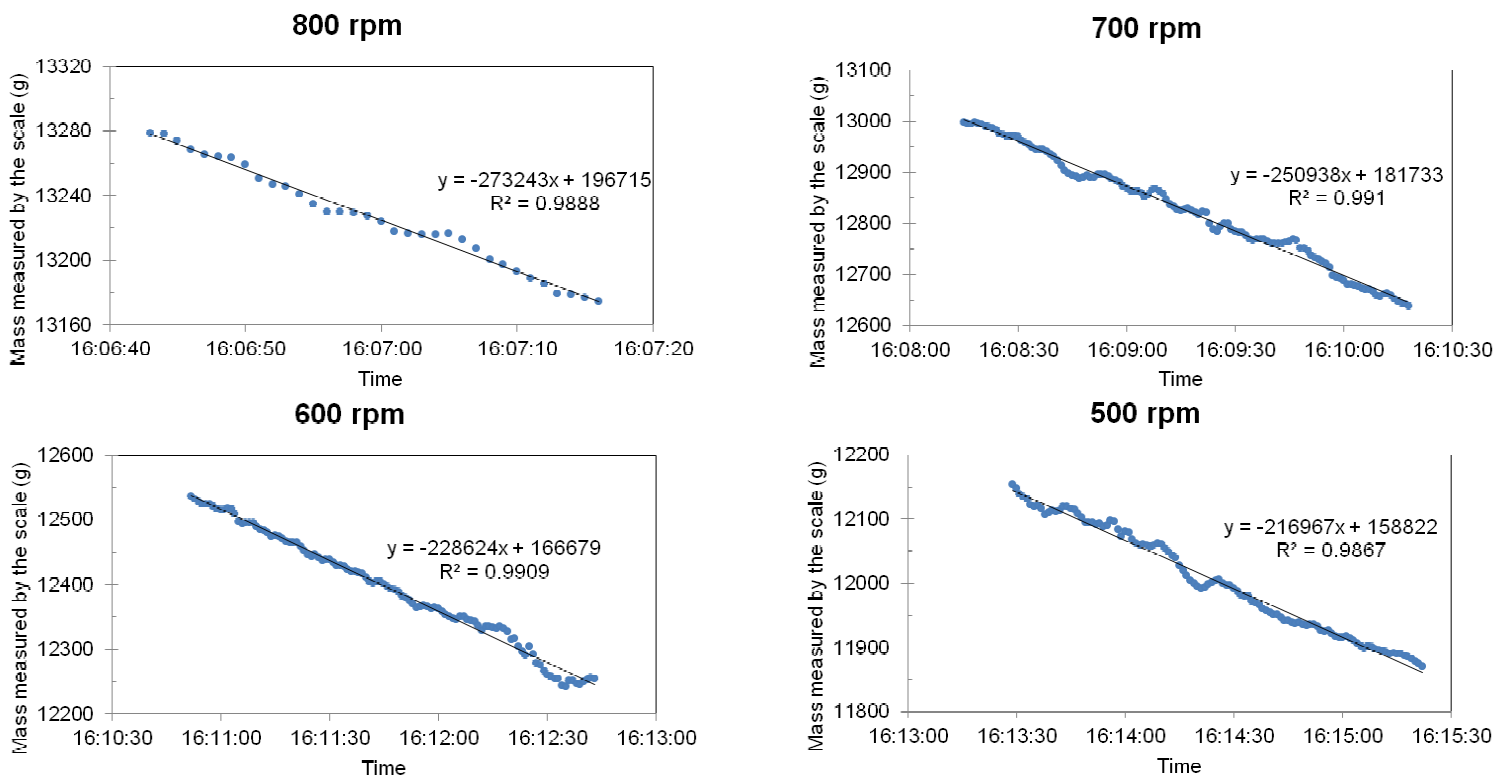

$400 \mathrm{rpm}$
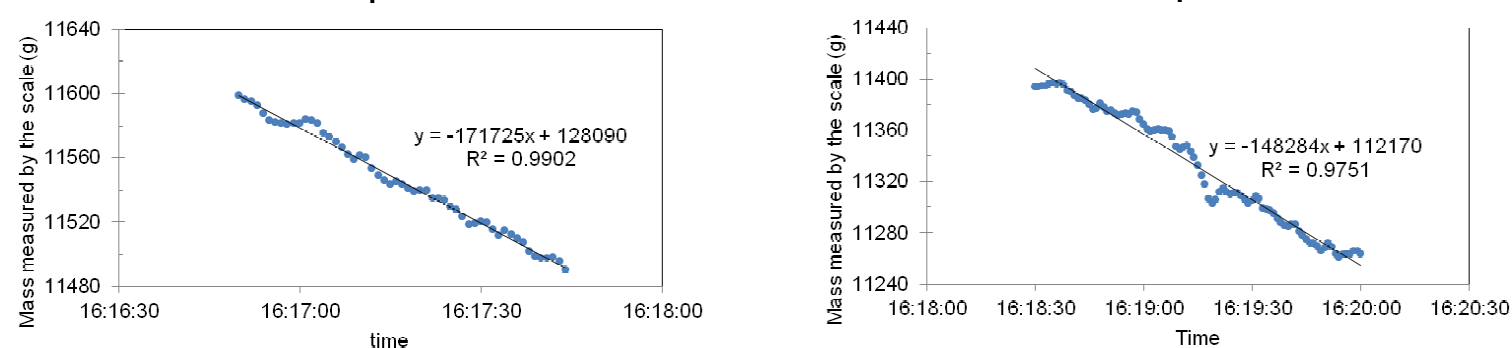

Fig. 5. Trend line equations corresponding to several stabilized PTO-speeds (indicated in each graph); notice that the time labels in abscissa are strings "hour:minute:second" but the spreadsheet (MS Excel) internally keeps them into account as absolute time values (in seconds) calculated from the beginning of the day (the midnight of the previous day is equal to the absolute time " $0 \mathrm{~s}$ ") 

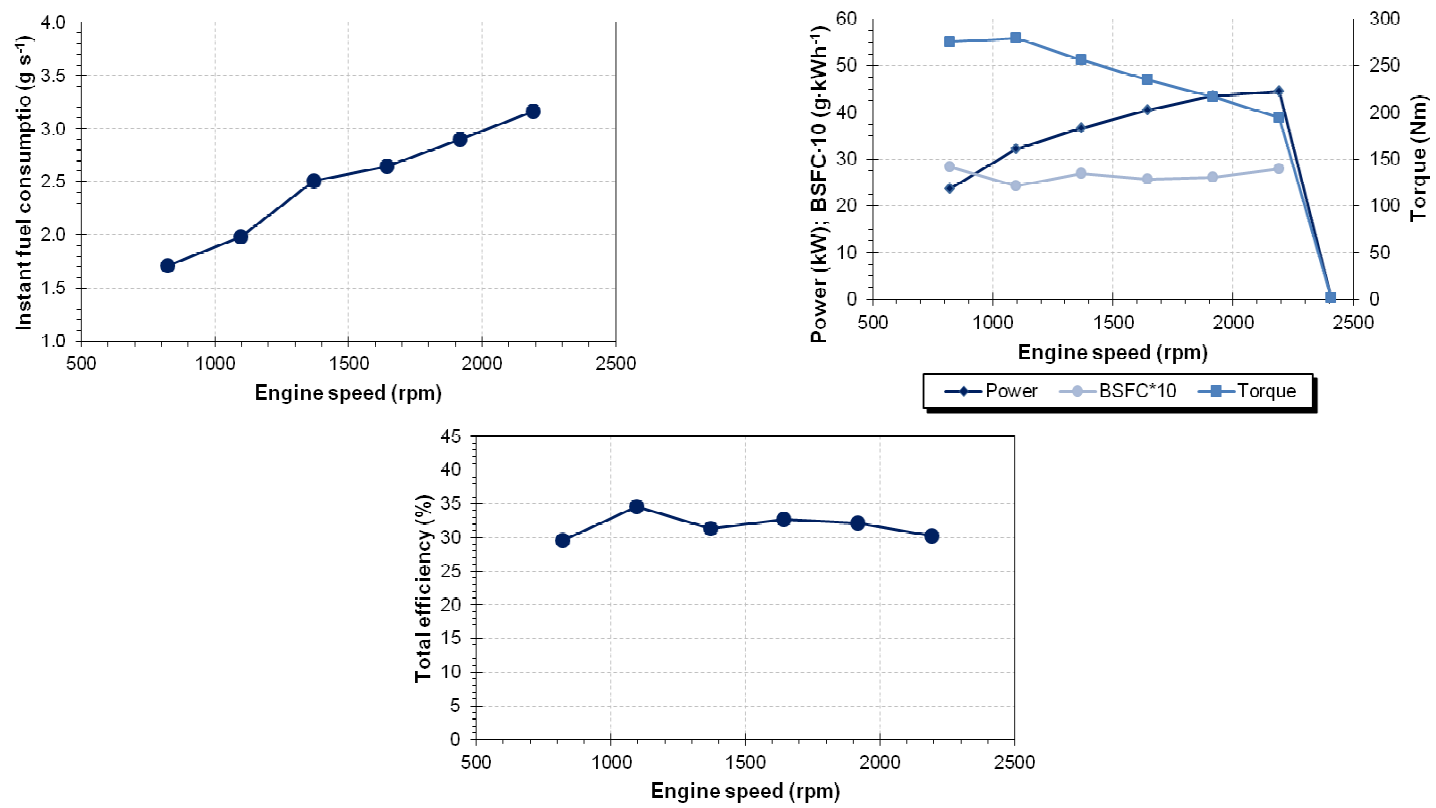

Fig. 6. Instant fuel consumptions, characteristic curves (among them: the BSFC - brake specific (mass) fuel consumption), total efficiency of tested engine in its complete speed range and at full-throttle

\section{Conclusions}

Starting from a critical survey of the different solutions adopted by other scholars to measure the fuel consumptions of agricultural machines in their respective works, a fuel-consumption meter system specifically thought to be used during tests of agricultural tractors at the dyno has been conceptualized, realized and experimented. It has the following characteristics: it is based on the chrono-gravimetric principle, it is able to carry many litres of fuel, thus warranting the possibility to perform also medium-length tests without refuelling, it has a closed-loop water refrigeration system, able to limit the temperature increment that normally happens during tests making use of low-capacity external tanks, responsible for alteration of results. Thanks to the chosen components, the heredescribed system can be utilized with every type of tractors (it is really universal) without any modification to the fuel line, while its global cost is lower than 1400 EUR (VAT excl.) - 1700 EUR (VAT incl.). After having verified that it has a negligible time-delay in the mass acquisition and a sufficient sensitivity, it has been successfully used to measure the instant/specific fuel consumption and the engine efficiency of a New Holland 4020V tractor during the test at the PTO-dyno.

\section{Acknowledgements}

The authors wish to thank the "Consorzio Agrario di Bolzano" (the "Farmers' cooperative of Bolzano", Italy; www.ca.bz.it/) for having put at the scholars' disposal the farm tractor used in this study within the collaboration agreement started on February 20, 2017 with the DYNOTRACTOR project ("Experimental setup of an in-field test apparatus for farm tractors").

\section{References}

[1] Mazzetto F., Bietresato M. "Proposal of a Local Telemetry Network for the Monitoring the Thermodynamic and Environmental Performances of Farm Tractors," J. Agric. Eng., 44, 2013, pp. 132-136.

[2] Siemens J. C., Bowers W. W. Machinery Management: How to Select Machinery to Fit the Real Needs of Farm Managers, Deere \& Company, East Moline, IL, 1999.

[3] Grisso R. D., Kocher M. F., Vaughan D. H. "Predicting Tractor Fuel Consumption," Appl. Eng. Agric., 20(5), 2004, pp. 553-561.

[4] Masek J., Novak P., Jasinskas A. "Evaluation of Combine Harvester Operation Costs in Different Working Conditions," Engineering for Rural Development, Latvia University of Agriculture, Jelgava, Latvia, 2017, pp. 1180-1185. 
[5] Bietresato M., Pavan S., Cozzi G., Sartori L. "A Numerical Approach for Evaluating and Properly Setting Self-Propelled Forage Harvesters," Trans. ASABE, 56(1), 2013, pp. 5-14.

[6] Ranjbarian S., Askari M., Jannatkhah J. "Performance of Tractor and Tillage Implements in Clay Soil,” J. Saudi Soc. Agric. Sci., 16(2), 2017, pp. 154-162.

[7] Damanauskas V., Velykis A., Satkus A. "Dependence of Fuel Consumption of Medium Power Tractor on Different Soil and Tire Deformations," Engineering for Rural Development, Latvia University of Agriculture, Jelgava, Latvia, 2017, pp. 515-520.

[8] Simikic M., Tomic M., Savin L., Micic R., Ivanisevic I., Ivanisevic M. "Influence of Biodiesel on the Performances of Farm Tractors: Experimental Testing in Stationary and Non-Stationary Conditions," Renew. Energy, 121, 2018, pp. 677-687.

[9] Karparvarfard S. H., Rahmanian-Koushkaki H. "Development of a Fuel Consumption Equation: Test Case for a Tractor Chisel-Ploughing in a Clay Loam Soil," Biosyst. Eng., 130, 2015, pp. 23-33.

[10] Almaliki S., Alimardani R., Omid M. "Fuel Consumption Models of MF285 Tractor under Various Field Conditions,” Agric. Eng. Int. CIGR J., 18(3), 2016, pp. 147-158.

[11] Šarauskis E., Vaitauskienè K., Romaneckas K., Jasinskas A., Butkus V., Kriaučiūnienė Z. "Fuel Consumption and CO2 Emission Analysis in Different Strip Tillage Scenarios," Energy, 118, 2017, pp. 957-968.

[12] Damanauskas V., Janulevičius A. "Differences in Tractor Performance Parameters between Single-Wheel 4WD and Dual-Wheel 2WD Driving Systems," J. Terramechanics, 60, 2015, pp. 63-73.

[13] Janulevičius A., Juostas A., Pupinis G. "Engine Performance during Tractor Operational Period," Energy Convers. Manag., 68, 2013, pp. 11-19.

[14] Kolator B., Białobrzewski I. "A Simulation Model of 2WD Tractor Performance," Comput. Electron. Agric., 76(2), 2011, pp. 231-239.

[15] Ilves R., Kuut A., Kuut K., Olt J. "The Impact of Multifunctional Biodiesel Fuel Additive on Diesel Engine Combustion Process," Engineering for Rural Development, Latvia University of Agriculture, Jelgava, Latvia, 2017, pp. 369-377.

[16]Lukes M., Kotek M., Ruzicka M. "Comparison of Transport Systems in Rural and Suburbanized Areas with Regards to Energy Consumption and Travel Speed," Engineering for Rural Development, Latvia University of Agriculture, Jelgava, Latvia, 2015, pp. 342-347.

[17] Pitla S. K., Luck J. D., Werner J., Lin N., Shearer S. A. "In-Field Fuel Use and Load States of Agricultural Field Machinery," Comput. Electron. Agric., 121, 2016, pp. 290-300.

[18] Graurs I., Laizans A., Rajeckis P., Rubenis A., "Public Bus Energy Consumption Investigation for Transition to Electric Power and Semi-Dynamic Charging," Engineering for Rural Development, Latvia University of Agriculture, Jelgava, Latvia, 2015, pp. 366-371.

[19] Kreicbergs J., Makarchuk D., Zalcmanis G., Grislis A. "City Driving Element Combination Influence on Car Traction Energy Requirements," Engineering for Rural Development, Latvia University of Agriculture, Jelgava, Latvia, 2015, pp. 272-277.

[20] Lynnworth L. C., Liu Y. "Ultrasonic Flowmeters: Half-Century Progress Report, 1955-2005," Ultrasonics, 44, 2006, pp. e1371-e1378.

[21]Bietresato M., Renzi M., Mischiatti S., Mazzetto F. "Engine Test Stand Layout and Post Processing Tools for the Detection of Many Engine Performance Parameters," ARPN J. Eng. Appl. Sci., 11(2), 2016.

[22]Renzi M., Bietresato M., Mazzetto F. "An Experimental Evaluation of the Performance of a SI Internal Combustion Engine for Agricultural Purposes Fuelled with Different Bioethanol Blends," Energy, 115, 2016, pp. 1069-1080.

[23] Bietresato M., Calcante A., Mazzetto F. "A Neural Network Approach for Indirectly Estimating Farm Tractors Engine Performances," Fuel, 143, 2015, pp. 144-154.

[24] Emberger P., Hebecker D., Pickel P., Remmele E., Thuneke K. "Emission Behaviour of Vegetable Oil Fuel Compatible Tractors Fuelled with Different Pure Vegetable Oils," Fuel, 167, 2016, pp. 257-270.

[25] Vojtisek-Lom M., Pechout M., Mazac M. "Measurement of Consumption Rates of Viscous Biofuels," Fuel, 107, 2013, pp. 448-454. 
[26] Bietresato M., Friso D. "Durability Test on an Agricultural Tractor Engine Fuelled with Pure Biodiesel (B100)," Turkish J. Agric. For., 38(2), 2014, pp. 214-223.

[27]Friso D. "Brake Thermal Efficiency and BSFC of Diesel Engines: Mathematical Modeling and Comparison between Diesel Oil and Biodiesel Fueling," Appl. Math. Sci., 8(130), 2014, pp. 6515- 6528.

[28] Rajabi Vandechali M., Hossein Abbaspour-Fard M., Rohani A. "Development of a Prediction Model for Estimating Tractor Engine Torque Based on Soft Computing and Low Cost Sensors," Measurement, 2018.

[29] Park Y., Hwang J., Bae C., Kim K., Lee J., Pyo S. "Effects of Diesel Fuel Temperature on Fuel Flow and Spray Characteristics," Fuel, 162, 2015, pp. 1-7.

[30] Reddemann M. A., Mathieu F., Martin D., Kneer R. "The Influence of Fuel Properties on Spray Propagation, Atomization and Evaporation," Proceedings of the 23rd Annual Conference on Liquid Atomization and Spray Systems (ILASS), Brno, Czech Republic, 2010.

[31] "Kern Platform Scale DS" [online][16.04.2018] Available: https://www.kern-sohn.com/cgibin/cosmoshop/lshop.cgi?action $=$ showdetail\&wkid $=152492128620844 \& 1 \mathrm{~s}=$ en\&nochache $=$ 1524921287-20843\&rubnum $=$ produkte. $197.200 \&$ artnum $=$ DS \%7C- \%7C- \%7C200.

[32] "Radwag PS 6000.R2 Precision Balance - Datasheet" [online][16.04.2018] Available: http://radwag.com/en/ps-6000-r2-precision-balance,w1,DMG,101-102-112\#5.

[33] "Froment SIGMA 50 Dynamometers" [online][16.04.2018] Available: http://www.fromentdynamometers.com/sigma-50-dynamometers.html.

[34]ENEA (Italian national agency for new technologies energy and the sustainable economic development), 2018, "Potere Calorifico [Heat of Combustion]" [online][16.04.2018]Available: http://www.enea.it/it/seguici/le-parole-dellenergia/glossario/parole/potere-calorifico. 